\title{
Sigmoid Sinus Dural Arteriovenous Malformation Resulting from Jugular Foramen Schwannoma
}

\section{-Case Report-}

\author{
Iwao YAMAKAMI, Junichi ONO, and Akira YAMAURA
}

Department of Neurosurgery, Chiba University School of Medicine, Chiba

\begin{abstract}
A 69-year-old male presented with a jugular foramen schwannoma occluding the sigmoid sinus and associated with sigmoid sinus dural arteriovenous malformation. The patient presented with dizziness and pulsatile tinnitus following an extended period of hearing loss beginning several years before. Both lesions were resected successfully after transarterial embolization of the malformation. The sequence of symptom development suggests the dural sinus thrombosis caused the dural arteriovenous malformation.
\end{abstract}

Key words: dural arteriovenous malformation, jugular foramen, schwannoma, sinus thrombosis

\section{Introduction}

Dural arteriovenous malformations (AVMs) may result from congenital factors as shown by occurrence in infancy and characteristic angiographic features, ${ }^{1,2)}$ but most dural AVMs are acquired. ${ }^{4,6]}$ Dural AVM may develop after trauma, ${ }^{4}$ surgery, ${ }^{14]}$ and dural sinus thrombosis. ${ }^{4,6)}$ Dural sinus thrombosis is regarded as the causative event in cases of acquired dural AVM. ${ }^{4}$ Dural AVM may develop in various intracranial sites, but two-thirds of cases involve the transverse or sigmoid sinus. ${ }^{3]}$

Tumors near the sigmoid sinus often infiltrate and occlude the sinus. Jugular foramen schwannomas comprise $2.9 \%$ to $4 \%$ of intracranial schwannomas. ${ }^{11,13)}$ Angiography shows that one third of jugular foramen schwannomas completely occlude the jugular bulb and the sigmoid sinus, ${ }^{11)}$ and jugular foramen schwannoma is associated with a high incidence of sinus thrombosis. We describe a case of jugular foramen schwannoma associated with a sigmoid sinus dural AVM.

\section{Case Report}

A 69-year-old male had noted loss of hearing in the right ear for many years. A recent otological examination had been unrevealing. He developed intermit-

Received June 19, 1997; Accepted October 14, 1997 tent dizziness and pulsatile tinnitus several months prior to hospital admission on July 26, 1994. On admission, auscultation revealed a bruit in the right retromastoid region. Lower cranial nerve function was intact. Audiometry indicated thresholds of 45 $\mathrm{dB}$ on the right and $25 \mathrm{~dB}$ on the left. Auditory brainstem responses to right-sided stimuli detected no response except for peak I. Otological examination suggested a retrocochlear lesion. Magnetic resonance imaging revealed a dumbbell-shaped tumor near the right jugular foramen extending in the intra- and extracranial directions (Fig. 1). Angiography revealed a dural AVM supplied by the right external carotid artery and involving the right sigmoid sinus. The right jugular bulb and proximal sigmoid sinus were occluded. The dural AVM was cross-drained via the torcular sinus to the opposite transverse and sigmoid sinuses (Fig. 2).

The patient underwent transarterial embolization of the dural AVM using polyvinylalcohol particles (150 to $250 \mu \mathrm{M}$ ). His pulsatile tinnitus was ameliorated by the embolization. The jugular foramen tumor and dural AVM were then resected using a transjugular approach. ${ }^{5]}$ The vestibulocochlear nerve in the cerebellopontine angle cistern was compressed and displaced rostrally by the intradural tumor. The tumor filled the jugular bulb and sigmoid sinus where angiography had revealed occlusion (Fig. 3). The histological diagnosis of the resected tumor was schwannoma. 

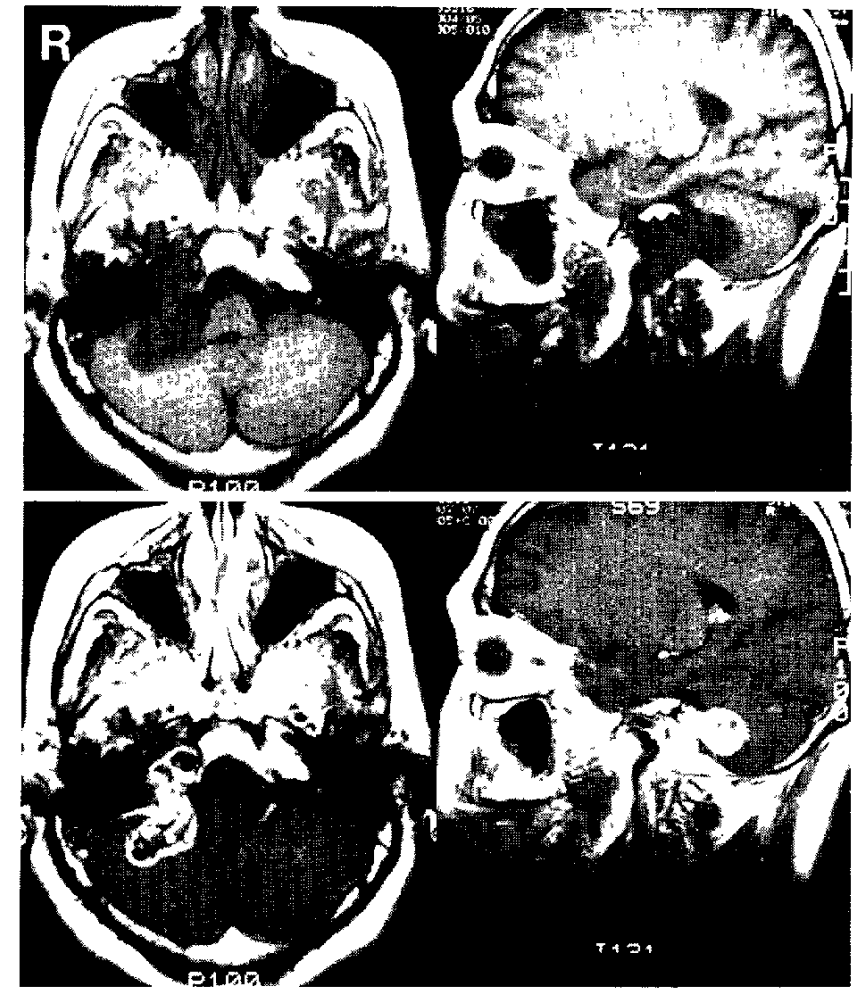

Fig. 1 T $T_{1}$-weighted magnetic resonance images obtained before (upper row) and after gadolinium-diethylenetriaminepenta-acetic acid administration (lower row) showing a dumbbell-shaped tumor in the right jugular foramen extending intra- and extracranially.
Postoperative angiography showed complete obliteration of the dural AVM (Fig. 4).

\section{Discussion}

Previously, angiography has shown dural AVM was preceded by dural sinus thrombosis in two cases, ${ }^{\text {i] }}$ and multiple dural AVMs evolved from sinus thrombosis induced by transvenous embolization in one case. $^{8)}$ Brain tumors near dural sinuses often infiltrate the sinus and cause thrombosis. Superior sagittal sinus occlusion by a parasagittal meningioma is fairly common. ${ }^{16)} \mathrm{A}$ case of meningioma involving the sigmoid sinus groove and associated with sigmoid sinus thrombosis and dural AVM involving the transverse sinus suggested that sinus thrombosis due to tumor involvement had caused development of the dural AVM. ${ }^{15}$

Dural AVMs most frequently involve the transverse and sigmoid sinuses." Schwannoma is the most common of the many tumors occurring near the jugular foramen. ${ }^{12)}$ Jugular foramen schwannomas often occlude the sigmoid sinus. ${ }^{11)}$ The present patient had a jugular foramen schwannoma, sigmoid sinus thrombosis, and a sigmoid sinus dural AVM. The chronology of development of these lesions, presumably in the order of jugular foramen schwannoma, sinus thrombosis, then dural AVM, was not proven by serial angiography spanning the period of dural AVM formation. However, the patient developed hearing loss several years before the onset of pulsatile tinnitus. Such hearing loss is consistent with the observed compression of the
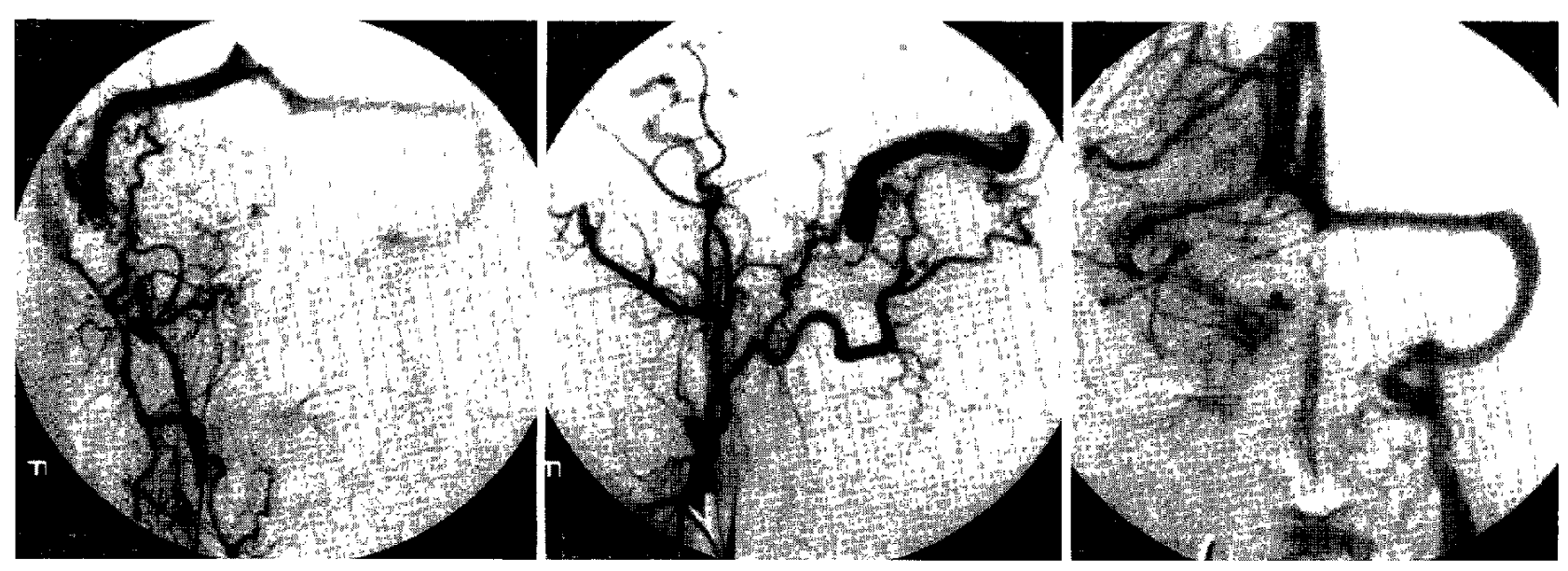

Fig. 2 Right external carotid angiograms (left, center) showing dural arteriovenous malformation of the right sigmoid sinus with cross-drainage via the torcular sinus to the opposite transverse and sigmoid sinuses and jugular vein. Right internal carotid angioram, venous phase (right), showing the right jugular bulb and sigmoid sinus are occluded, probably by the hypovascular jugular foramen tumor. 


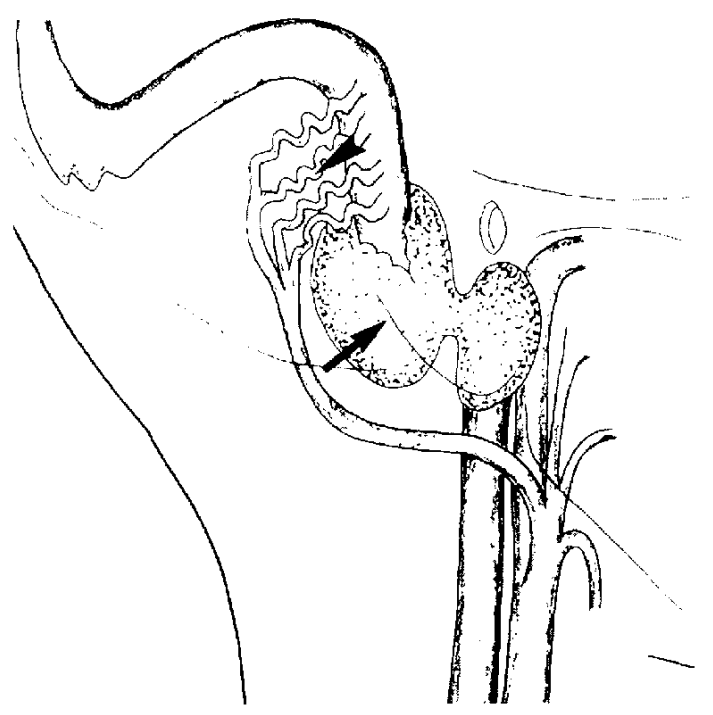

Fig. 3 Schema showing the jugular foramen schwannoma, sigmoid sinus thrombosis, and sigmoid sinus dural arteriovenous malformation (AVM). The right dumbbellshaped jugular foramen schwannoma has totally filled the jugular bulb and sigmoid sinus (arrow). There is an associated sigmoid sinus dural AVM (arrowhead).

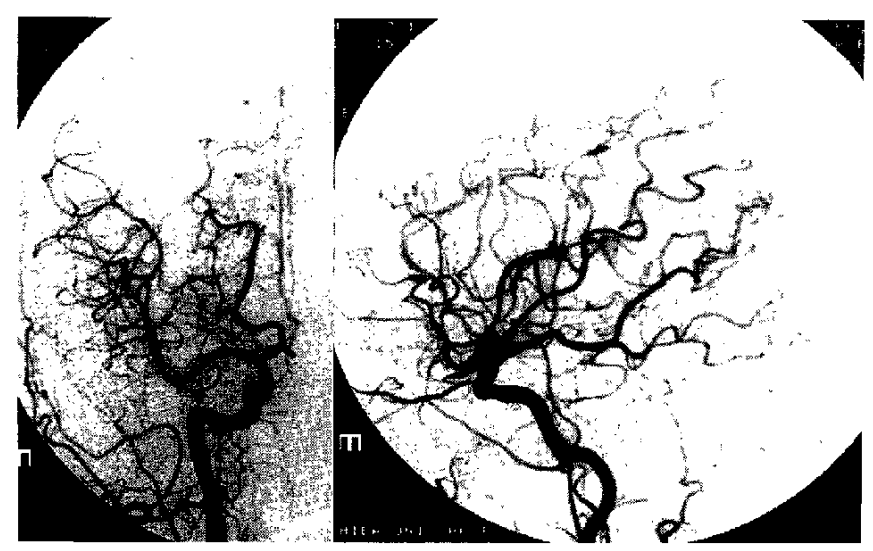

Fig. 4 Right carotid angiograms after surgical resection of the schwannoma and the dural arteriovenous malformation indicating no residual lesion.

cochlear nerve ${ }^{9 l}$ by the jugular foramen schwannoma in the cerebellopontine angle. Pulsatile tinnitus, the most common symptom of dural AVM involving the transverse and sigmoid sinuses, ${ }^{7,10)}$ occurred later in the present case and was ameliorated by embolization of the dural AVM. The link between the tumor and the dural AVM was sigmoid sinus thrombosis due to tumor involvement. Despite the absence of an angiogram preceding dural AVM formation, the symptom progression is convincing evidence of the causative sequence in this case.

\section{References}

1) Albright AL, Latchaw RE, Price RA: Posterior dural arteriovenous malformations in infancy. Neurosurgery 13: 129-135, 1983

2) Aminoff MJ: Vascular anomalies in the intracranial dura mater. Brain 96: 601-612, 1973

3) Awad IA, Little JR, Akrawi WP, Ahl J: Intracranial dural arteriovenous malformations: factors predisposing to an aggressive neurological course. $J$ Neurosurg 72: 839-850, 1990

4) Chaudhary MY, Sachdev VP, Cho SH, Weitzner I Jr, Puljic S, Huang YP: Dural arteriovenous malformation of the major venous sinuses: An acquired lesion. AJNR Am J Neuroradiol 3: 13-19, 1982

5) Hakuba A, Hashi K, Fujitani K, Ikuno H, Nakamura $T$, Inoue Y: Jugular foramen neurinomas. Surg Neurol 11: 83-94, 1979

6) Houser OW, Campbell JK, Campbell RJ, Sundt TM Jr: Arteriovenous malformation affecting the transverse dural venous sinus - an acquired lesion. Mayo Clin Proc 54: 651-661, 1979

7) Lasjaunias $P$, Chiu $M$, ter Brugge $K$, Tolia $A$, Hurth M, Bernstein M: Neurological manifestations of intracranial dural arteriovenous malformations. J Neurosurg 64: 724-730, 1986

8) Nakagawa H, Kubo $S$, Nakajima $Y$, Izumoto $S$, Fujita $\mathrm{T}$ : Shifting of dural arteriovenous malformation from the cavernous sinus to the sigmoid sinus to the transverse sinus after transvenous embolization. A case of left spontaneous carotid-cavernous sinus fistula. Surg Neurol 37: 30-38, 1992

9) Neely GL: Reversible compression neuropathy of the eight cranial nerve from a large jugular foramen schwannoma. Arch Otolaryngol 105: 555-560, 1979

10) Оьгаdor S, Soto M, Silvela J: Clinical syndromes of arteriovenous malformations of the transverse-sigmoid sinus. J Neurol Neurosurg Psychiatry 38: 436-451, 1975

11) Samii M, Babu RP, Tatagiba M, Sepehrnia A: Surgical treatment of jugular foramen schwannomas. J Neurosurg 82: 924-932, 1995

12) Samii M, Draf W: Surgery of the Skull Base. Berlin, Springer-Verlag, 1989, pp 359-428

13) Tan LC, Bordi L, Symon L, Cheesman AD: Jugular foramen neurinomas: A review of 14 cases. Surg Neurol 34: 205-211, 1990

14) Ugrinovski J, Vrcakovski $M$, Lozance K: Dural arteriovenous malformation secondary to meningioma removal. Br J Neurosurg 3: 603-608, 1989

15) Yokota M, Tani E, Maeda Y, Yamaura I: Meningioma in sigmoid sinus groove associated with dural arteriovenous malformation: Case report. Neurosurgery 33: 316-319, 1993 
16] Zülch KJ: Brain Tumors. Berlin, Springer-Verlag, 1986, pp 357-383
Address reprint requests to: I. Yamakami, M.D., Department of Neurosurgery, Chiba University School of Medicine, 1-8-1 Inohana, Chuo-ku, Chiba 260, Japan. 